\title{
The Kuroshio exchange with the South and East China Seas
}

\author{
T. Matsuno ${ }^{1}$, J.-S. Lee ${ }^{2}$, and S. Yanao ${ }^{3}$ \\ ${ }^{1}$ Research Institute for Applied Mechanics, Kyushu University, Japan \\ ${ }^{2}$ Ocean Research Team, National Fisheries Research \& Development Institute, Korea \\ ${ }^{3}$ Department of Earth System Science and Technology, Kyushu University, Japan
}

Received: 1 April 2009 - Published in Ocean Sci. Discuss.: 21 April 2009

Revised: 8 July 2009 - Accepted: 10 July 2009 - Published: 3 August 2009

\begin{abstract}
The Kuroshio flows along the edges of the marginal East Asian seas such as the South China Sea (SCS) and East China Sea (ECS). Exchanges of materials and energy between the Kuroshio and the marginal seas partly control the environments of the marginal seas. In particular, saline water from the Kuroshio maintains certain salinity in the shelf water in the ECS. Nutrients from the subsurface of the Kuroshio may influence primary production on the shelf. We summarize how the Kuroshio comes into contact with the shelf water or marginal seas, describing phenomena related to the exchange between the Kuroshio and the ECS along with the SCS, using reports in the literature along with original data. The Kuroshio tends to intrude into the SCS through the Luzon Strait in various manners such as direct intrusion, associated with eddies and as a loop current. The Kuroshio intrusion into the shelf region of the ECS has distinct seasonal variation and the Taiwan Warm Current plays a significant role in the determination of water properties in the outer shelf associated with the Kuroshio intrusion. We then examine physical processes related to the interaction between the Kuroshio and shelf water. Interaction between the Kuroshio and the bottom topography is an important process in the control of the exchange around the shelf break. Vertical mixing and frontal eddies are also important factors that control the water exchange and formation of water masses in the outer shelf. Wind stress plays a significant role in the exchange with a rather event-like manner. To determine the source of the water masses, chemical tracers could be powerful tools and it is suggested that a significant part of the shelf water consists of Kuroshio intermediate water.
\end{abstract}

Correspondence to: $\mathrm{T}$. Matsuno (matsuno@riam.kyushu-u.ac.jp)

\section{Introduction}

Marine environments around shelves and in marginal seas usually depend on a supply of nutrients from land, particularly in regions influenced by a large amount of fresh water from rivers. On the other hand, nutrient supply from the open ocean could be significant even in inland seas as discussed by Yanagi and Ishii (2004); e.g., in the Seto Inland Sea, Japan. The nutrient budget for the shelf region of the East China Sea (ECS) was calculated using a box model by Chen and Wang (1999), who found that the nutrient supply to the shelf region from the open ocean could exceed that from Changjiang. However, it is not clear yet how the nutrients could be supplied to the euphotic zone in the shelf region and what fraction of the nutrients from the open ocean could be used for primary production. Furthermore, physical processes of the nutrient supply regarding how the nutrients are introduced to the shelf from the open ocean are not well known, whereas there are several candidates for the major processes of water exchange between the open ocean and shelf water, such as frontal eddies along the Kuroshio, bottom intrusion around the shelf break, and upwelling caused by topography or wind fields.

Exchange between the open ocean and shelf is strongly related to the behavior of the Kuroshio in the ECS. The Kuroshio, a major western boundary current in the North Pacific, flows into the ECS east of Taiwan, turns right owing to topography, flows along the continental slope, and then flows to the Pacific through the Tokara Strait. When the Kuroshio flows into the ECS through the deep sill between the islands of Taiwan and Yonaguni, it faces the continental slope and turns right following the bottom topography, while the current field in the region is strongly related to fluctuations in the Kuroshio. Fluctuation in the Kuroshio passage may be due to interaction between the Kuroshio and mesoscale eddies

Published by Copernicus Publications on behalf of the European Geosciences Union. 
propagating from the east (Ichikawa et al., 2008). Depending on the direction of the Kuroshio and bottom topography northeast of Taiwan, a complicated current field can arise in the area, such as a cyclonic cold eddy northeast of Taiwan (Tang et al., 2000). Inertia of the Kuroshio can result in part of the Kuroshio water intruding into the shelf region with upward motion. The constraint of bottom topography on the rotating fluid would make it difficult for the current to intrude into shallow regions, particularly in the weak stratification in winter. However, baroclinic motion of the stratified fluid would make it possible for part of the Kuroshio to have cross-isobath motion. This would result in significant interaction between the shelf and deep waters. Another exchange between the shelf and the deep ocean would exist around the shelf break. Frontal eddies frequently seen along the Kuroshio around the shelf break and outer shelf could enhance the interaction between the Kuroshio and shelf water.

In this paper, we summarize phenomena related to the exchange between the Kuroshio and the shelf observed in the ECS and South China Sea (SCS), and discuss dynamical processes concerning the exchange.

\section{Contact between the Kuroshio and shelf water and marginal seas}

\subsection{Kuroshio intrusion into the SCS}

The SCS is the biggest marginal sea in East Asia and has a wide shelf area. However, the main exchange with the Pacific Ocean occurs through the Luzon Strait and there is a deep ocean in the northern part of the SCS, while there is a deep sill with complicated topography in the Luzon Strait. There are various viewpoints concerning the Kuroshio intrusion into the SCS. Hu et al. (2000) summarized four explanations of the behavior of the Kuroshio around the Luzon Strait: a direct branch from the Kuroshio, loop current, extension of the Kuroshio-influenced water and formation of a ring. The latter two explanations appear to be variations or generalized expressions of the former two. A direct branch is a rather traditional explanation and was discussed by early investigators such as Nitani (1972). A loop current is a relatively recent explanation. A loop was clearly shown in a numerical model presented by Metzger and Hurburt (2001).

In general, part of the Kuroshio flows into the SCS from the south or central part of Luzon Strait, and a significant part of the inflow returns to the main stream of the Kuroshio through the northern part of the strait, forming a loop current. Meanwhile, part of the inflow from the Kuroshio flows to the shallow area near the Taiwan Strait, in some cases becoming a source of the Taiwan Strait Current (TaSC), which can be distinguished from the Taiwan Warm Current (TaWC) found in the shelf region in the ECS. The fraction that returns to the main stream of the Kuroshio through the Luzon Strait seems to depend on the season. Using data from the ARGO drifters,
Centurion et al. (2004) found Kuroshio intrusion only in winter, although there was a loop current in all seasons in the numerical model of Metzger and Hurburt (2001).

Contrary to the suggestion from numerical experiments, Yuan et al. (2006) showed that the Kuroshio loop current was not a stationary feature around the Luzon Strait, using the sea level anomaly based on altimeter data obtained over a long period. Particularly the stationary loop current was rarely found in winter, and even in summer most of the loop currents were associated with the passage of anticyclonic eddies. They also showed that a direct northwestward intrusion through the Luzon Strait is frequently found in winter. The strong intrusion often appears to flow westward passing through the northern SCS to the western shelf.

The direct intrusion that intensifies in winter was recently reproduced in numerical experiments. Using results from a numerical model validated with ADCP data taken from moorings in the Luzon Strait, Liang et al. (2008) showed that the location and intensity of the South China Sea Cyclonic Flow has a great influence on the Kuroshio intrusion across the Luzon Strait. The Kuroshio intrusion is intensified by a large scale cyclonic eddy in the SCS basin that is enhanced in winter.

As we discuss later, the volume transport of the TaSC through the Taiwan Strait has large seasonal variation, being large in summer and small in winter. The seasonal variation in the volume transport through the Taiwan Strait is quite different to the variation through the Luzon Strait. It is not clearly understood how the exchange between the Kuroshio and the shelf water in the SCS through the Luzon Strait is related to the current field in the Taiwan Strait.

\subsection{Kuroshio intrusion into the shelf area of the ECS}

Most of the Kuroshio east of Taiwan flows into the ECS passing over a sill shallower than $1000 \mathrm{~m}$ between Taiwan and western end of Ryukyu Islands. The Kuroshio then impinges on the continental slope, resulting in a turn to the east. Study of the current system in the ECS began earlier than study of the current system in the SCS, and various schematic views of the current fields in the ECS have been proposed since 1930. Some suggest that there is a Kuroshio branch flowing into the shelf area. In fact, as mentioned later, considering the difference in volume transport between the Taiwan and Tsushima Straits, Kuroshio intrusion onto the shelf is necessary from mass conservation.

One of the most probable sites for the Kuroshio to intrude into the shelf region is northeast of Taiwan. An intensive investigation - the Kuroshio Edge Exchange Processes (KEEP) study - has been carried out in the region by scientists from Taiwan and the United States since 1989. One of the results of the project was the revelation that a significant intrusion of the Kuroshio into the East China Sea shelf occurred from autumn through winter and was associated with monsoon events (Tang and Yang, 1993; Chuang 
and Liang, 1994). They suggested a seasonal variation in the Kuroshio axis and strength northeast of Taiwan. However, it was also shown that there were significant fluctuations with various time scales. The other study during KEEP suggests that most of the nutrient supply to the shelf region comes from the Kuroshio subsurface. The research also indicates that the cross-shelf transport of dissolved and particulate materials may be important for carbon budget, and a cyclonic eddy formed at the shelf edge northeast of Taiwan could significantly contribute to the exchange of the materials (Wong et al., 2000). Other literatures suggest that a cold eddy frequently exists just northeast of Taiwan and is associated with the eastward turning of the Kuroshio (Hsueh, 2000; Tang et al., 2000). The region is dynamically complicated because of the abrupt change in the bottom topography, strong current of the Kuroshio, outflow of TaSC from the Taiwan Strait and other factors. Ichikawa et al. (2008) discussed the fluctuation in the Kuroshio path in the area northeast of Taiwan on the basis of data obtained with high-frequency (HF) radar operated at Yonaguni and Ishigaki. They suggested that eddies affect the location of the Kuroshio passage. The temporal variation in the current fields has been obtained not only from $\mathrm{HF}$ radar but also using an altimeter. However, the shelf region is too far from the HF radar stations and the reliability of the altimetry is not high because of the lack of in situ data.

As mentioned above, the Kuroshio intrusion into the shelf area is related to the volume transport of the TaSC flowing into the shelf region of the ECS from the Taiwan Strait and the volume transport of the Tsushima Warm Current (TsWC) flowing out to the Japan Sea through the Tsushima Strait (Fig. 1). The volume transport through the Tsushima Strait has been accurately deduced over 10 years by crossstrait monitoring using an acoustic Doppler current profiler (ADCP) mounted on a ferry (Takikawa et al., 2005). However, the volume transport through the Taiwan Strait is not known well owing to the large variation in and short measurement periods for data recorded by moored systems, although there have been various reports on the volume transport in various seasons (Teague et al., 2003; Liang et al., 2003; Lin et al., 2005; Jan et al., 2006). Isobe (2008) summarized the seasonal variation in volume transport through the Taiwan Strait; around $2.5 \mathrm{~Sv}$ in June and almost zero in winter. Comparing the volume transport through the Taiwan Strait with that through the Tsushima Strait, the net transport of the Kuroshio intrusion into the shelf region can be estimated. Indeed, Teague et al. (2003) calculated the net transport from the Kuroshio into the shelf using volume transport obtained with ten bottom mounted ADCPs deployed in the Taiwan and Tsushima Straits. However, the period was limited to only three months because of the short term measurements from just October to December in the Taiwan Strait. The time series showed that northward transport through the Taiwan Strait gradually decreased from October to December, with predominant short time scale variations that appeared related to the wind field. The net transport from the

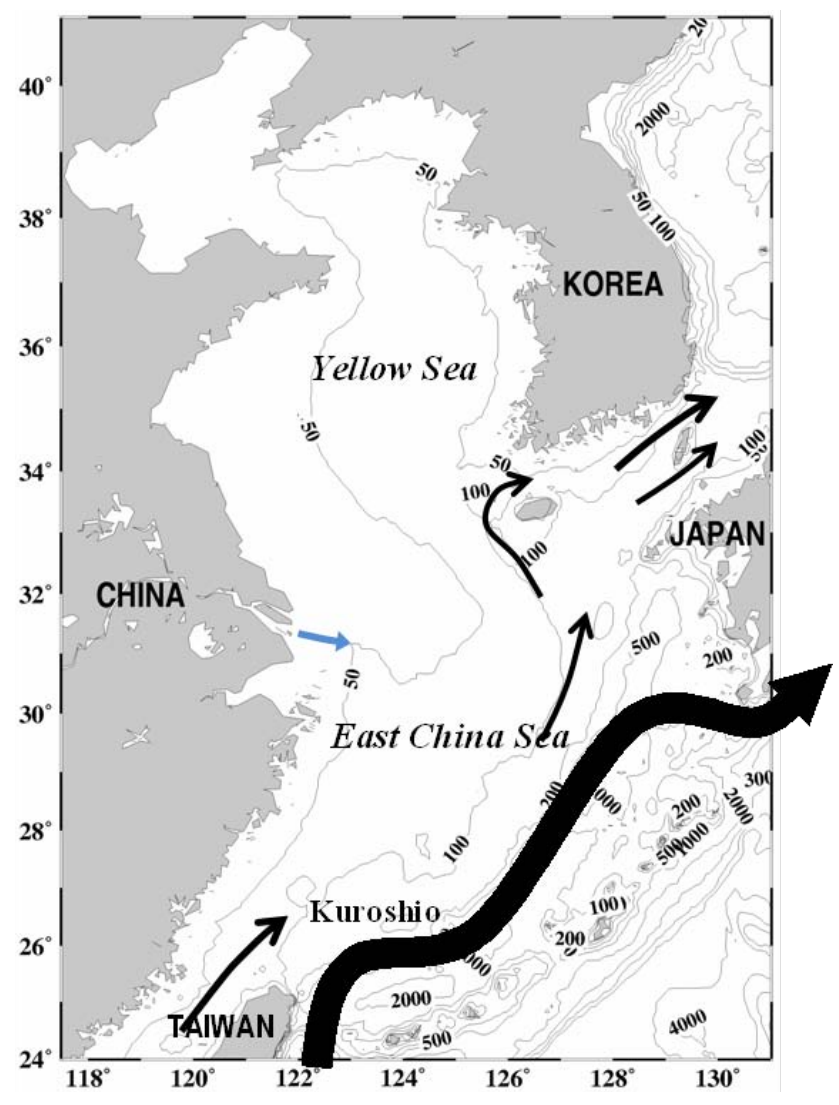

Fig. 1. Bottom topography and schematic view of the current field in the ECS.

Kuroshio to the shelf region was about $3 \mathrm{~Sv}$ which was averaged for the three months. They also calculated the temperature and salinity transport through each strait using the observed volume transport along with climatological data, and suggested there was a small contribution of the water masses from the Taiwan Strait. Their results based on direct measurements suggest a significant contribution of Kuroshio water to the water masses on the shelf. However, their data was obtained from just a short period, and so it will be necessary to obtain much longer time series of volume transport through the Taiwan Strait to properly discuss the physical processes connected with the net transport of Kuroshio intrusion.

The Kuroshio intrusion depends on various conditions of the shelf, such as stratification, the intensity of the TaWC, tidal mixing, and the wind. Results for a numerical model constructed by Lee and Matsuno (2007) revealed intrusion of the Kuroshio subsurface water into the shelf region, particularly in summer when an intensified TaWC interacts with the Kuroshio intrusion. The interaction between the TaWC and Kuroshio intrusion is discussed in the next section. 


\subsection{Interaction of the TaWC and Kuroshio flowing onto the shelf}

As mentioned in the previous section, the volume transport of the TaSC flowing northeastward in the Taiwan Strait has distinct seasonal variation. The volume transport is large in summer and small or mostly zero in winter. However, the behavior of the TaSC is not yet known with certainty; for example, the transport through the Taiwan Strait in winter has gradually decreased in research conducted in the past decade, as summarized by Isobe (2008). However, it is commonly believed that the decrease in the transport in winter is to a large extent due to the northeast monsoon. An intensified northeasterly wind in winter is correlated to a reduced northward current in the Taiwan Strait (Jan et al., 2006), while the fluctuation in the volume transport is large.

Therefore, it is expected that there is no interaction between the TaWC and Kuroshio intrusion for a mean field in winter. In summer on the other hand, the volume transport of the TaSC is significant and the TaWC may interact with the Kuroshio intrusion north of Taiwan. In summer, the transport of the TaSC can exceed 2 Sv (Jan et al., 2006). The northeastward current through the Taiwan Strait carries slightly less saline water than the Kuroshio from SCS to ECS. An enhanced TaWC could prevent the Kuroshio intruding into the shelf region in summer. However, the TaWC is restricted to an upper layer shallower than the water depth of the outer shelf because the Taiwan Strait is shallower than $60 \mathrm{~m}$. Therefore, the Kuroshio subsurface water could intrude into the shelf region beneath the TaWC.

Indeed, numerical experiments have suggested that the Kuroshio subsurface water intrudes into the shelf region in front of the Changjiang river mouth (Lee and Matsuno, 2007). Figure 2 shows the distribution of tracer put in the upper and middle layers of the Kuroshio east of Taiwan. The Kuroshio water does not enter the shelf region through the upper layer. Instead, the Kuroshio subsurface water intrudes into the shelf region in summer. Both upper and subsurface waters of the Kuroshio are prevented entering the shelf region in winter. In the case of winter, the constraint of the bottom topography due to the homogeneity of the water could prevent the current from crossing the isobath. However, the numerical model used climatological boundary conditions for the TaSC and specified $0.9 \mathrm{~Sv}$ for the transport in winter. This might be larger than the actual volume transport, as it was based on Wang et al. (2003) where the data were limited. At this time we do not have reliable values for the transport. Guo et al. (2006) also discussed Kuroshio intrusion onto the shelf using a numerical model. They found clear seasonal variations in the Kuroshio intrusion onto the shelf that are strongly related to the transport from the Taiwan Strait. In their model, the Kuroshio intrudes onto the shelf even in winter owing to the weakened TaWC. The difference between their results and those of Lee and Matsuno (2007) suggest that the Kuroshio intrusion strongly depends on the

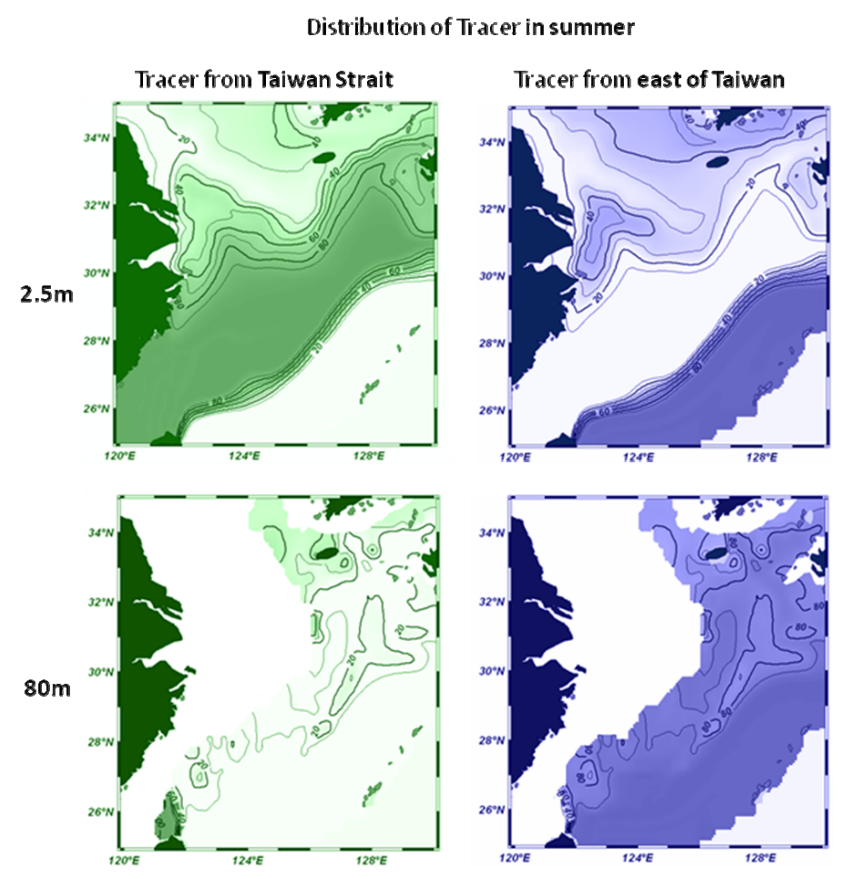

Fig. 2. Distribution of a tracer released (upper) at the surface and (lower) in the subsurface in (left) the Taiwan Strait and (right) east of Taiwan in summer based on the results of a numerical experiments conducted by Lee and Matsuno (2007).

TaWC, even in winter. Lie and Cho (2002) also suggest that a reduced volume transport of the TaSC could enhance the Kuroshio intrusion onto the middle shelf area; however, it is difficult to describe the mean current field because of the lack of observed data.

Regardless of the intrusion of the Kuroshio, the area northeast of Taiwan is a very complicated area requiring the consideration of two major currents, bottom topography, stratification, tidal motion and wind effects. The current field presented by Tang et al. (2000) using a ship board ADCP and mapping of the sea surface temperature from satellite data by Hsueh (2000) suggest the existence of a cold core associated with a cyclonic eddy. We deployed two satellite-tracking drifters in the northern Taiwan Strait, and their trajectories initially revealed a clockwise eddy before one drifter appeared to ride a cyclonic eddy. Collision of the Kuroshio on the shelf break and eddies of various scales generated northeast of Taiwan could mix the water of the Kuroshio and the TaWC. Hsueh (2000) used an interesting term - a mixing mill - to describe the role of the cyclonic eddy northeast of Taiwan. The mixing could produce a specific water mass along the outer shelf region of the ECS.

If cross-shelf currents or eddies are formed in association with the Kuroshio intrusion, significant mixing would be expected northeast of Taiwan, and the mixed water could flow along the isobaths just shelf side of the Kuroshio. Indeed, there is observational evidence for the formation of outer 


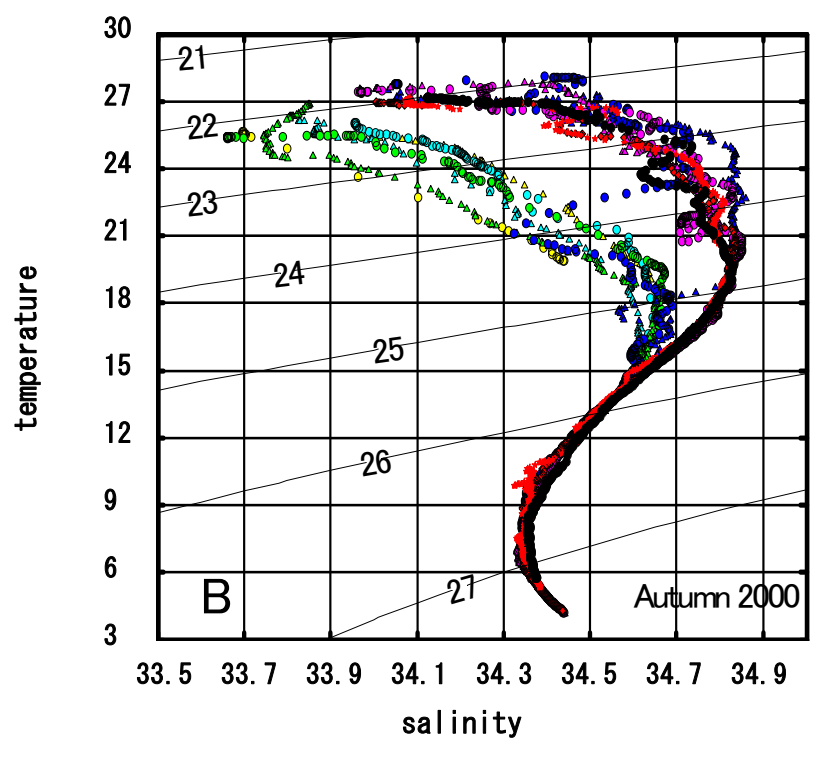

Fig. 3a. T/S diagram along B section, shown in Fig. 3c, across the Kuroshio obtained in Autumn 2000.

shelf water. As an example, a temperature-salinity diagram obtained for a section across the Kuroshio during a cruise in 2000 reveals two water masses (Fig. 3). Histograms of the frequency distribution of salinity show two modes at each isopycnal. The less saline water is distributed over the outer shelf region. The water mass sometimes occupies the shelf slope region and has a volume transport greater than that of the TaSC, which means that the outer shelf water is not only from the Taiwan Strait but is a mixture of the Kuroshio and water from the Taiwan Strait. Historical data show that outer shelf water is frequently identified in the region around the shelf break in summer and autumn.

\section{Factors and physical processes relating to the interac- tion between the Kuroshio and shelf water}

\subsection{Bottom topography and geographical configuration}

There are two passages for flow into and out of the ECS other than inflow and outflow of the Kuroshio; namely, the Taiwan Strait and Tsushima Strait. As mentioned above, the volume transport through both straits is not the same. Isobe (2008) proposed a schematic consideration. It is difficult for a steady current to cross geostrophic contours unless there is another forcing such as strong friction. Therefore, the explanation of the current field illustrated in Fig. $4 \mathrm{a}$ is difficult to accept; though such a current in reality cannot be completely denied because of its nonlinearity or transient state. The explanation illustrated in Fig. 4b is more easily accepted since there is a boundary and friction could play a significant role. This means intrusion of the Kuroshio water into the shelf region could occur more easily northeast of Taiwan than west of Kyushu in a dynamical sense. However, in some transient states, intrusion of the Kuroshio into the shelf region could be enhanced particularly in autumn as discussed by Isobe (1999).

On the other hand, stratification may play another role in producing a cross-isobath current. The spatial difference in the vertically integrated density could generate a vorticity in a sloping bottom region. It is usually referred as the joint effect of baroclinicity and relief (JEBAR) in discussing the influence of the bottom topography on the stratified fluid (e.g., Mertz and Wright, 1992). Analyzing the results of numerical experiments, Guo et al. (2006) revealed that cross-shelf advection of the geostrophic current can be predominantly balanced with the JEBAR along the $200 \mathrm{~m}$ isobath in the ECS, while seasonal variation in the cross-shelf advection strongly depends on wind stress. On the other hand, there is a spatial distribution of the onshore flux along the shelf break, and the temporal variation in the cross-shelf advection of the geostrophic current is mainly explained by a change in the JEBAR term, instead of wind stress. An interaction between the stratification and bottom topography could allow onshore flux across the shelf break.

\subsection{Vertical mixing generated by internal waves}

Quantitative evaluation of vertical mixing is generally a crucial issue in understand not only water exchange processes but also general circulation. Around the shelf break in the ECS, vertical mixing caused by internal waves or interaction between the Kuroshio and bottom topography could play an important role in the cross shelf exchange. Han et al. (2001) revealed that short time scale internal waves frequently exist near the shelf break in the ECS. Comparing the variance of band-passed current velocity with temporal variations in the vertical gradient of temperature, it was suggested that the short time scale internal waves exist just above or below the thermocline. It was also suggested that the short time scale internal waves could generate vertical mixing resulting in a change in stratification, while no feature of the vertical mixing itself was described. Following the study by Han et al. (2001), Matsuno et al. (2005) showed intermittent intensification of the vertical mixing associated with internal waves on the basis of measurements of the microscale structure. Repeated hydrographic surveys across the shelf break showed that the vertical structure formed by an intensified thermocline and bottom or intermediate mixed layer could change day by day (Han et al., 2001).

A series of these studies revealed that internal waves intermittently generated around the shelf break could induce enhanced vertical mixing, and consequently change the stratification. Change in the vertical structure could generate ageostrophic flow with a short response time, which may induce a cross-shelf water exchange. The process could explain offshore intrusion that is sometimes suggested by a high-turbidity tongue as shown in Fig. 5. 

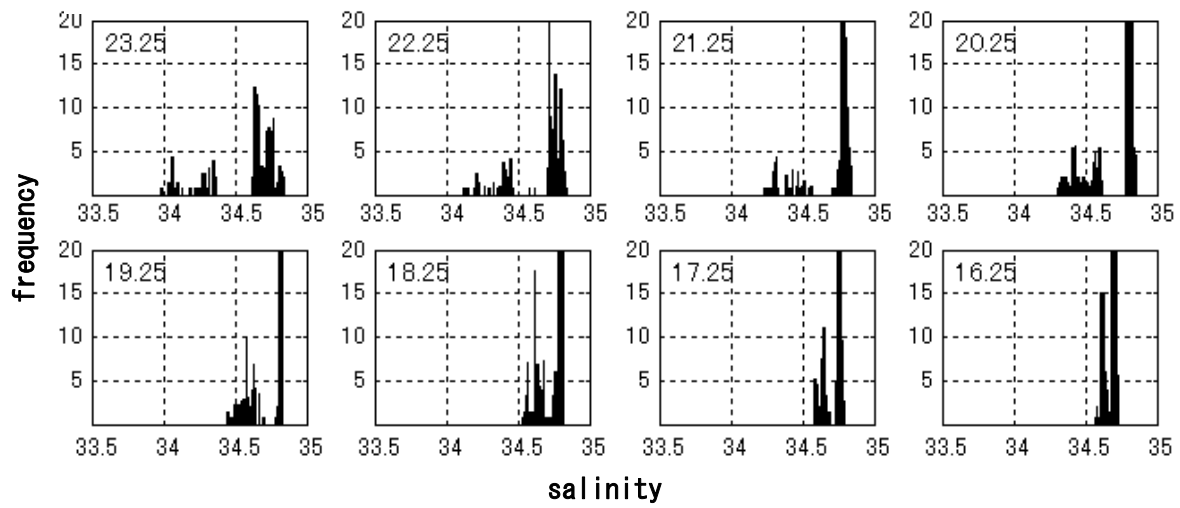

Fig. 3b. Histograms of salinity found around each isopycnals shown at the left-upper corner of each panel.

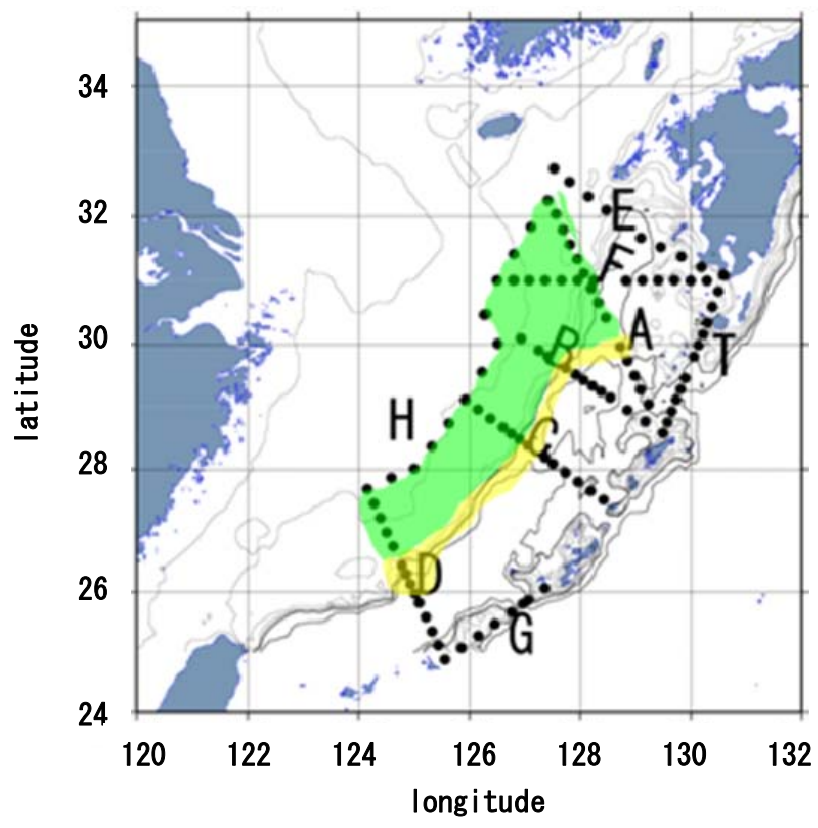

Fig. 3c. Outer shelf water defined by the second mode with slightly less saline water than the Kuroshio occupies the area shown in green. The yellow area shows the transient region to the Kuroshio.

\subsection{Frontal processes and cross-shelf exchange}

In general, the Kuroshio flows stably along the continental slope in the ECS. However, there are frequent frontal eddies along the Kuroshio in satellite images. It is not easy to detect the eddies by usual observations from research vessels because of their fine structure and short-period variations. Instead, in association with the frontal eddies, we can show a few observation results suggesting that shelf water could intrude into the subsurface of the Kuroshio. This is a kind of subduction of the surface water on the shelf. Figure 6 shows an example of low-salinity water subduction along the Kuroshio front detected from repeated observations over
3 days. The location of the front changed quickly probably owing to downstream propagation of the frontal eddy associated with the Kuroshio. The low salinity tongue is subducted, mostly along the isopycnals near the salinity front. However, strictly speaking, the low-salinity tongue seemed to sink slightly against the isopycnals. The subduction must be associated with three-dimensional frontal eddies, instead of simply with a vertical section. Subduction of the surface water associated with frontal eddies was discussed by Spall (1995) using a numerical model. He showed development of subduction associated with baroclinic instability, resulting in ageostrophic cross-front flows. Isobe et al. (2004) represented salinity inversion around the shelf break in the ECS using a numerical model. They explained the salinity inversion by the difference in propagation speeds for surface and subsurface layers of frontal waves generated by baroclinic instability. Considering that the low-salinity water subduction slightly crossed the isopycnals in a vertical section, a three-dimensional process should be considered in explaining the tongue shape distribution. It is difficult to directly measure the subduction velocity in the field.

Another example of the shelf water subduction is shown in Fig. 7. In this case, low-salinity water subducts approximately along the isopycnals and contains much dissolved oxygen. This reveals low-salinity and high-oxygen shelf surface water intruding offshore along the isopycnal front of the Kuroshio around the shelf break, while there must be movement along the shelf.

\subsection{Wind stress}

Movement of the surface water in the shelf region is strongly controlled by wind fields. As described above, numerical model experiments show that the seasonal variation in the total cross-shelf transport along the shelf break is strongly related to the wind stress, most of which is caused by Ekman transport (Guo et al., 2006).

In the shelf region, the behavior of fresh water discharged from Changjiang is strongly controlled by wind fields on the 


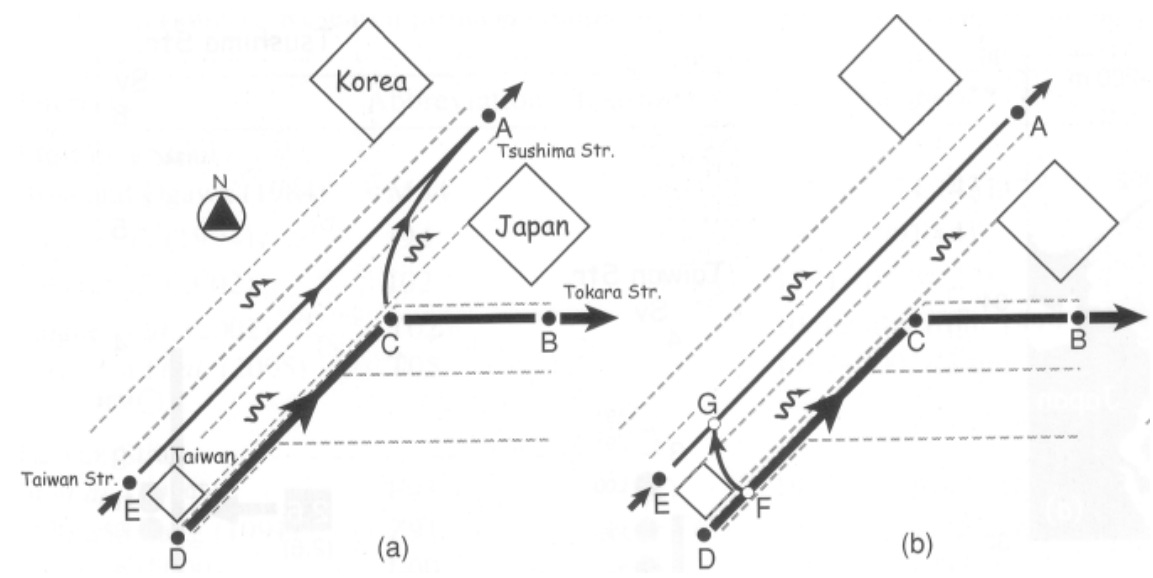

Fig. 4. Schematic diagrams of ocean-current paths in the thought experiments of Isobe (2008) (reproduced with permission of the Oceanographic Society of Japan who has the copyright).

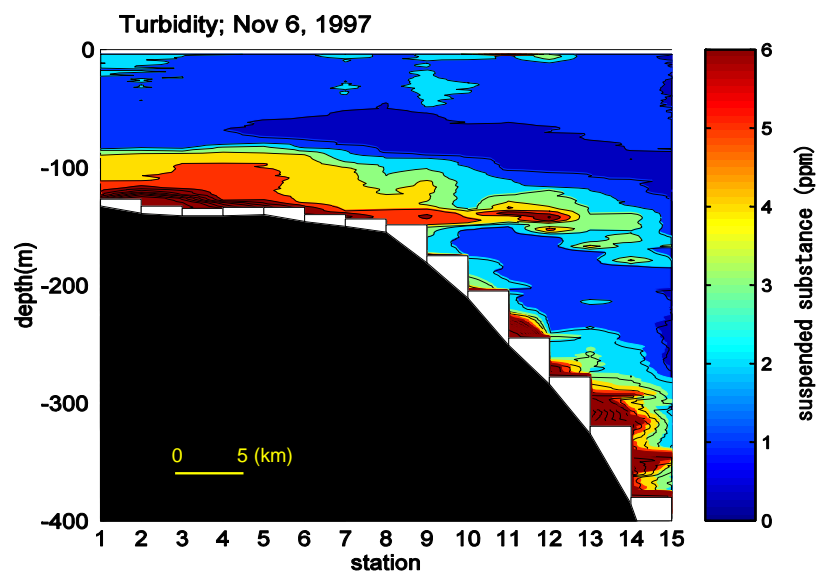

Fig. 5. Vertical section of turbidity obtained in November 1997 suggesting that bottom water on the shelf intrudes into the intermediate water of the Kuroshio.

shelf, not only in a climatological sense (Chang and Isobe, 2003) but also on a shorter time scale (Yuan and Qiao, 2005). Furthermore, a significant proportion of nutrient supply for primary production in the shelf area could come from the subsurface of the Kuroshio. The upward transport of the nutrients in the lower layer on the shelf could be generated by wind stirring and surface divergence caused by wind fields such as that of a typhoon. Comparing the distributions of nutrients, chlorophyll-a, and primary and bacterial productivity after the passage of a typhoon with those under normal conditions, Shiah et al. (2000) and Chen et al. (2003) clearly showed there was a significant supply of nutrients for biological production, though the study area was in the northern part of the Taiwan Strait. In the outer shelf of the ECS, Siswanto et al. (2007) showed a clear statistical relationship between the passage of a typhoon and primary production, based on the chlorophyll determined from a satellite dataset. Matsuno et al. (2009) suggested there was significant upward transport of nutrient rich water from the lower layer as a result of the passage of a tropical depression in the mid-shelf of the ECS. In those cases, nutrient rich water in general originates at the Kuroshio subsurface. This means that the wind effect on the shelf could enhance the interaction between deep ocean and shelf water.

\subsection{Chemical evidence}

As mentioned above, the net transport from the Kuroshio into the shelf area of the ECS could be calculated from the difference in volume transport between the Taiwan Strait and Tsushima Strait. However, if we consider the possibility of inflow from the subsurface and outflow from the surface layer, exchange between the Kuroshio and shelf waters cannot be estimated from the net transport. The origins of the water masses have been examined using chemical properties, such as the composition of oxygen or radium isotopes, nutrients, dissolved oxygen, and rare earth elements (REE). Kim et al. (2005) described how the TsWC waters are a mixture of waters originating from the Taiwan Strait and those originating directly from the Kuroshio using the composition ratio of the oxygen isotope and salinity for the waters around Jeju Island. Zhang et al. (2007) used a radium (Ra) isotope as well as temperature and salinity to estimate the mixing proportion among four water masses; Kuroshio Surface Water, Kuroshio Subsurface Water (KSSW), Changjiang Diluted Water and Taiwan Strait Warm Water. They mentioned the advantage of using the Ra isotope as a tracer as being its non-particlereactive nature. They showed a significant contribution of the KSSW, where it was defined by water at $100 \mathrm{~m}$ within the Kuroshio, to the surface water even in the inner shelf not far from Changjiang mouth. They also showed large variability in the mixing proportion. 

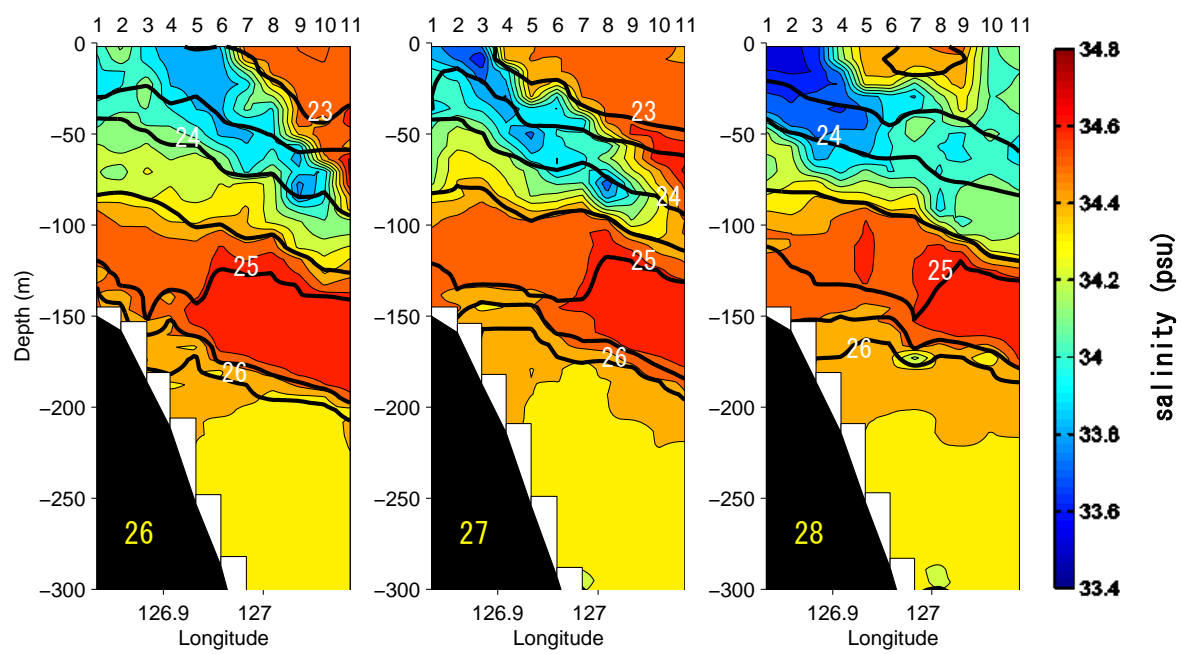

Fig. 6. Vertical section of salinity (color) and sigma-t (contours) observed along the same section across the Kuroshio on 26,27 and 28 May 1997. Numerals at the top of each panel indicate the locations of measurements.
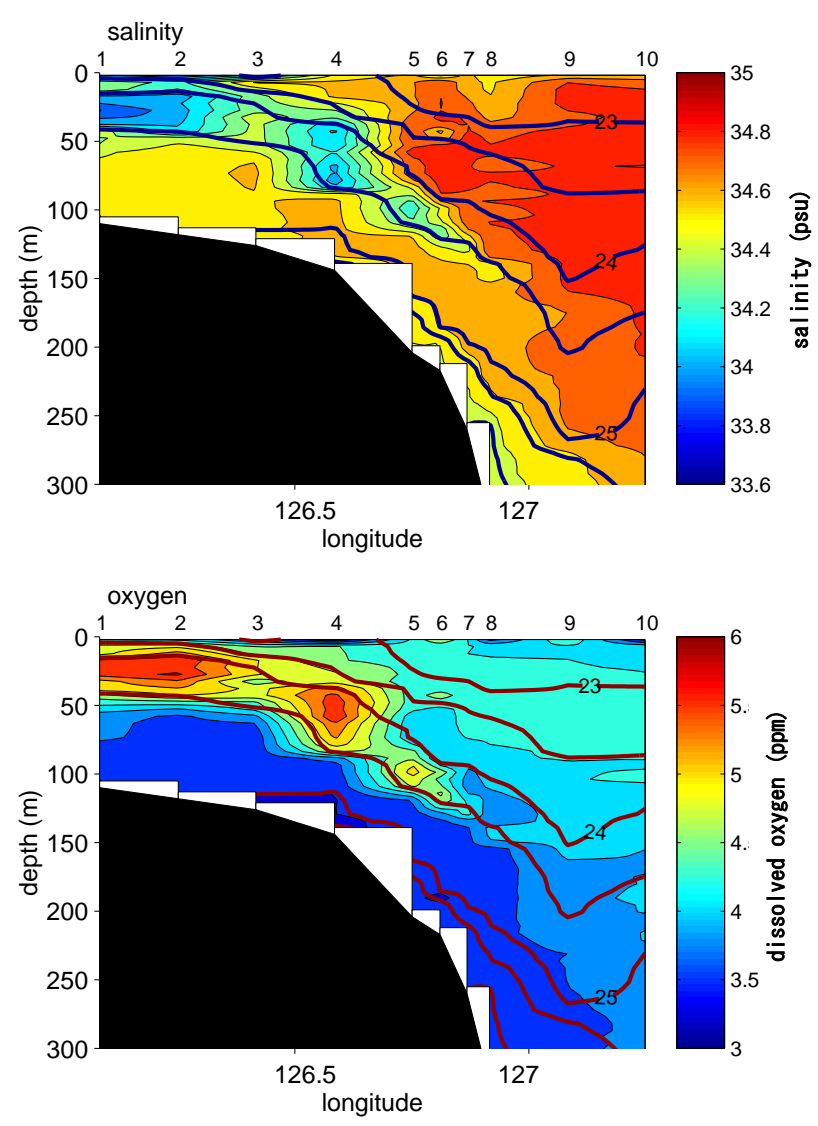

Fig. 7. Vertical section of (upper) salinity and (lower) dissolved oxygen observed along the section across the Kuroshio around the shelf break in May 2002. Contours show sigma-t. Numerals at the top of each panel indicate the locations of the measurement.
On the other hand, a recent study using the composition of REE as chemical tracers estimated that the Kuroshio Intermediate Water deeper than $200 \mathrm{~m}$ could be a significant component, about $1 / 3$, of the source for the bottom water on the shelf (Bai and Zhang, 2009).

\section{Concluding remarks}

In the SCS, "Deep Ocean Exchange with the Shelf" occurs in the central part of the marginal sea, and exchange through the Luzon Strait described in this paper is that between deep oceans because the northern part of the SCS has a deep basin. On the other hand, the ECS is a typical and complicated example of the exchange between the deep ocean and shelf water. A major factor concerning the exchange that plays an important role in the environment is the Kuroshio intrusion onto the shelf. Besides differences in the volume transports through the Taiwan and Tsushima Straits, compensating for part of the volume transport from the Kuroshio into the shelf region, shelf water should be transported offshore, where the outflow could involve water intruding from the Kuroshio. If we know the time series of the salinity distribution on the shelf and that at the open boundaries of the ECS as well as the time series of fresh water input, the water exchange could be evaluated properly as for the method for coastal ocean using the concept of the average residence time (Takeoka, 1984). However, we cannot find such a dataset except for a climatological database. Furthermore, whereas the residence time of the fresh water can be estimated from the salinity, it is difficult to estimate the residence time of the Kuroshio water on the shelf from the salinity. A chemical tracer could be used to obtain the residence time of shelf water as presented by Nozaki et al. (1989), who estimated the residence time of the 
shelf water as about 2.3 years using a $\mathrm{Ra}$ isotope. However, a tracer cannot provide enough information for the residence time of the Kuroshio water on the shelf.

Chemical tracers, such as REE, could be a powerful tool for identifying the source and mixing ratios of water masses on the shelf. If we could obtain a reliable ratio for each water mass, it would be possible to evaluate the degree of intrusion of the Kuroshio surface and intermediate waters combining with the net transport from the Kuroshio onto the shelf. We recommend using a greater number of water samples to advance analyses with chemical tracers.

Another important and attractive issue for future study of the exchange process between the Kuroshio and shelf water is the quantitative determination of vertical processes such as vertical mixing, upwelling, subduction and restratification. Various data obtained from satellite observations provide us with detailed and widely spread images of various properties in the ocean. Particularly in the region around the shelf break, there are usually clear differences in ocean color suggesting cross-shelf water exchange. However, it is rare to be able to obtain time series owing to cloud cover and there is no information about the vertical structure. ARGO data could provide vertical structure but such observations are limited to deep regions. We strongly recommend the examination of vertical processes in the ocean. Therefore, observations from research vessels are still important in determining what happens in the real ocean. Marginal seas such as the ECS are sometimes complicated by national borders and economic activities. It is important to progress international cooperative studies, which should establish a common understanding on the circulation and environment in the shelf region.

Acknowledgements. The authors would like to express their gratitude to the captains, officers and crew of the T/V Nagasaki-maru, Nagasaki University, for their assistance during the observations. This work was partly supported by a Grant-in-Aid for Scientific Research (KAKENHI18340143) from the Japan Society for the Promotion of Science and by the Special Funding for Education and Research entitled "Monitoring and Forecasting of the Rapid Change in Ocean-Atmosphere Environment in the East Asia" from Ministry of Education, Culture, Sports, Science and Technology, Japan.

Edited by: J. A. Johnson

\section{References}

Bai , L. and Zhang, J.: Shelf water mass origins and nutrient flux estimation in the East China Sea using low-volume seawater measurement with rare earth element, Adv. Geosci., in press, 2009.

Chang, P.-H. and Isobe, A.: A numerical study on the Changjiang Diluted Water in the East and Yellow China Seas, J. Geophys. Res., 108(C9), 3299, doi:10.1029/2002JC001749, 2003.

Chen, C. T. A. and Wang, S. L.: Carbon, alkalinity and nutrient budgets on the East China Sea continental shelf, J. Geophys. Res., 104(C9), 20675-20686, 1999.
Chen, C. T. A., Liu, C. T., Chuang, W. S., Yang, Y. J., Shiah, F.-K., Tang, T. Y., and Chung, S. W.: Enhanced buoyancy and hence upwelling of subsurface Kuroshio waters after a typhoon in the southern East China Sea, J. Marine Syst. 42, 65-79, 2003.

Centurion, L. R., Niiler, P. P., and Lee, D. K.: Observations of inflow of Philippine Sea surface water into the South China Sea through the Luzon Strait, J. Phys. Oceanogr., 34, 113-121, 2004.

Chuang, W.-S. and Liang, W.-D.: Seasonal variability of intrusion of the Kuroshio Water across the continental shelf northeast of Taiwan, J. Oceanogr., 50, 531-542, 1994.

Guo, X., Miyazawa, Y., and Yamagata, T. : The Kuroshio onshore intrusion along the shelf break of the East China Sea: the origin of the Tsushima Warm Current, J. Phys. Oceanogr., 36, 22052231, 2006.

Han, I.-S., Kamio, K., Matsuno, T., Manda, A., and Isobe, A.: High frequency current fluctuations and cross shelf flows around the pycnocline near the shelf break in the East China Sea, J. Oceanogr., 57, 235-249, 2001.

Hsueh, Y.: The Kuroshio in the East China Sea, J. Marine Syst., 24, 131-139, 2000.

Hu, J., Kawamura, H., Hong H., and Qi, Y.,: A review on the currents in the South China Sea seasonal circulation, South China Sea Warm Current and Kuroshio intrusion, J. Oceanogr., 56, 607-624, 2000.

Ichikawa, K., Tokeshi, R., Kashima, M., Sato, K., Matsuoka, T., Kojima S., and Fujii, S.: Kuroshio variations in the upstream region as seen by HF radar and satellite altimetry data, Int. J. Remote Sens., 29(21), 6317-6326, doi:10.1080/01431160802175454, 2008.

Isobe, A.: On the origin of the Tsushima Warm Current and its seasonality, Cont. Shelf Res., 19, 117-133, 1999.

Isobe, A.: Recent advances in ocean-circulation research on the Yellow Sea and East China Sea Shelves, J. Oceanogr., 64, 569-584, 2008.

Isobe, A., Fujiwara, E., Chang, P.-H., Sugimatsu, K., Shimizu, M., Matsuno, T., and Manda, A.: Intrusion of the less saline shelf water into the Kuroshio subsurface layer in the East China Sea, J. Oceanogr., 60(5), 853-863, 2004.

Jan, S., Sheu, D. D. and Kuo, H.-M.: Water mass and throughflow transport variability in the Taiwan Strait, J. Geophys. Res., 111, C12012, doi:10.1029/2006JC003656, 2006.

Kim, K.-R., Cho, Y.-K., Kang, D.-J., and Ki, J.-H.: The origin of the Tsushima Current based on oxygen isotope measurement, Geophys. Res. Lett., 32, L03602, doi:10.1029/2004GL021211, 2005.

Lee, J. S. and Matsuno, T.: Intrusion of Kuroshio water onto the continental shelf of the East China Sea, J. Oceanogr., 63, 309325, 2007.

Liang, W.-D., Tang, T.-Y., Yang, Y.-J., Ko, M.-T., and Chuang, W.S.: Upper-ocean currents around Taiwan, Deep-Sea Res. II, 50, 1085-1105, 2003.

Liang, W.-D., Yang, Y. J., Tang, T. Y., and Chuang,W.-S.: Kuroshio in the Luzon Strait, J. Geophys. Res., 113, C08048, doi:10.1029/2007JC004609, 2008.

Lie, H.-J. and Cho, C.-H.: Recent advances in understanding the circulation and hydrography of the East China Sea, Fish. Oceanogr., 11(6), 318-328, 2002.

Lin, S. F., Tang, T. Y., Jan, S., and Chen, C.-J.: Taiwan Strait current in winter, Cont. Shelf Res., 25, 1023-1042, 2005.

Matsuno, T., Shimizu, M., Morii, Y., Nishida, H., and Takaki, Y.: 
Measurements of the turbulent energy dissipation rate around the shelf break in the East China Sea, J. Oceanogr., 61(6), 10291037, 2005.

Matsuno, T., Han, I.-S., Kim, S.-H., Pang, I.-C., and Lee, J.-H.: Contribution of subsurface water to the salinity increase and primary production in the Changjiang Diluted Water, Pacific Oceanogr., in review, 2009.

Mertz, G. and Wright, D. G.: Interpretations of the JEBAR term, J. Phys. Oceanogr., 22, 301-305, 1992

Metzger, E. J. and Hurlburt, H. E.: The nondeterministic nature of Kuroshio penetration and eddy shedding in the South China Sea, J. Phys. Oceanogr., 31, 1712-1732, 2001.

Nitani, H.: Beginning of the Kuroshio, in: Kuroshio: Its Physical Aspects, edited by: Stommel, H. and Yoshida, K., 129-163, Univ. of Tokyo Press, Tokyo, 1972.

Nozaki, Y., Kasemsupaya, V., and Tsubota, H.: Mean residence time of the shelf water in the East China and the Yellow Seas determined by ${ }^{228} \mathrm{Ra} /{ }^{226} \mathrm{Ra}$ measurements, Geophys. Res. Lett., 16(11), 1297-1300, 1989.

Shiah, F. K., Chung, S. W., Kao, S. J., Gong, G. C., and Liu, K. K.: Biological and hydrographical responses to tropical cyclones (typhoons) in the continental shelf of the Taiwan Strait, Cont. Shelf Res., 20, 2029-2044, 2000.

Siswanto, E., Ishizaka, J., Yokouchi, K., Tanaka, K., and Tan, C. K.: Estimation of interannual and interdecadal variations of typhoon-induced primary production: A case study for the outer shelf of the East China Sea, Geophys. Res. Lett., 34, L03604, doi:10.1029/2006GL028368, 2007.

Spall, M.: Frontogenesis, subduction, and cross-front exchange at upper ocean fronts, J. Geophys. Res., 100(C2), 2543-2557, 1995.
Takeoka, H.: Fundamental concept of exchange and transport time scale in a coastal sea, Cont. Shelf Res., 3, 311-326, 1984.

Takikawa, T., Yoon, J. H., and Cho, K. D.: The Tsushima Warm Current through Tsushima Straits estimated from ferryboat ADCP data, J. Phys. Oceanogr., 35, 1154-1168, 2005.

Tang, T. Y. and Yang, Y. J.: Low frequency current variability on the shelf break northeast of Taiwan, J. Oceanogr., 49, 193-210, 1993.

Tang, T. Y., Tai, J. H., and Yang, Y. J.: The flow pattern north of Taiwan and the migration of the Kuroshio, Cont. Shelf Res., 20, 349-371, 2000.

Teague, W. J., Jacobs, G. A., Ko, D. S., Tang, T. Y., Chang, K. I., and Suk, M. S.: Connectivity of the Taiwan, Cheju and Korea strait, Cont. Shelf Res., 23, 63-77, 2003.

Wong, G. T. F., Chao, S. Y., Li, Y. H., and Shiah, F. K.: The Kuroshio edge exchange processes (KEEP) study - an introduction to hypotheses and highlights, Cont. Shelf Res., 20, 335-347, 2000.

Yanagi, T. and Ishii, D.: Open ocean originated phosphorus and nitrogen in the Seto Inland Sea, Japan, J. Oceanogr., 60, 10011005, 2004.

Yuan, D. and Qiao, F.: Cross-shelf penetrating front off the southeast coast of China observed by MODIS, Geophys. Res. Lett., 32, L19603, doi:10.1029/2005GL023815, 2005.

Yuan, D., Han, W., and Hu, D.: Surface Kuroshio path in the Luzon Strait area derived from satellite remote sensing data, J. Geophys. Res., 111, C11007, doi:10.1029/2005JC003412, 2006.

Zhang, L., Liu, Z., Zhang, J., Hong, G. H., Park, Y., and Zhang, H. F: Reevaluation of mixing among multiple water masses in the shelf: An example from the East China Sea, Cont. Shelf Res., 27, 1969-1979, 2007. 